\title{
Температурные зависимости электропроводности и магнитной восприимчивости кристаллов твердых растворов $\mathrm{Sb}_{2} \mathrm{Te}_{3}-\mathrm{Bi}_{2} \mathrm{Te}_{3}$
}

\author{
(C) Н.П. Степанов ${ }^{1,3}$, В.Ю. Наливкин ${ }^{1}$, А.К. Гильфранов ${ }^{1}$, А.А. Калашников ${ }^{2}$, Е.Н. Трубицына ${ }^{3}$ \\ 1 Забайкальский государственный университет, \\ 672036 Чита, Россия \\ 2 Забайкальский институт железнодорожного транспорта, \\ 672040 Чита, Россия \\ ${ }^{3}$ Забайкальский институт предпринимательства, \\ 672000 Чита, Россия \\ E-mail: np-stepanov@mail.ru
}

Поступила в Редакцию 12 августа 2021 г.

В окончательной редакции 28 августа 2021 г.

Принята к публикации 28 августа 2021 г.

\begin{abstract}
Твердые растворы $\mathrm{Bi}_{2} \mathrm{Te}_{3}-\mathrm{Sb}_{2} \mathrm{Te}_{3}$ продолжают оставаться предметом многочисленных и разносторонних экспериментальных исследований вследствие их практической значимости для термоэлектрического материаловедения. В связи с этим остается актуальной задача изучения закономерностей изменения состояния электронной системы этих полупроводников от состава и температуры. В данной работе приведены результаты исследования температурных зависимостей магнитной восприимчивости кристаллов $\mathrm{Bi}_{2} \mathrm{Te}_{3}-\mathrm{Sb}_{2} \mathrm{Te}_{3}$, содержащих 10, 25, 40, 50, 60 мол\% $\mathrm{Sb}_{2} \mathrm{Te}_{3}$. Анализируется корреляция поведения температурных зависимостей магнитной восприимчивости и удельной электропроводности.
\end{abstract}

Ключевые слова: магнитная восприимчивость, удельная электропроводность, кристаллы твердых растворов $\mathrm{Sb}_{2} \mathrm{Te}_{3}-\mathrm{Bi}_{2} \mathrm{Te}_{3}$.

DOI: 10.21883/FTP.2021.12.51700.17

\section{1. Введение}

В настоящее время продолжаются исследования кристаллов твердых растворов $\mathrm{Bi}_{2} \mathrm{Te}_{3}-\mathrm{Sb}_{2} \mathrm{Te}_{3}$, которые были предложены в качестве термоэлектрического материала еще в 50-х годах прошлого столетия, и сочетают в себе качества, позволяющие им оставаться одним из основных материалов в промышленном производстве термоэлектрических устройств [1]. Исследуются зависимости их физических характеристик от состава твердого раствора, температуры, типа и количества легирующей примеси. При этом в ряде случаев обнаруживается аномальное изменение величин, непосредственно влияющих на термоэлектрическую эффективность кристаллов $\mathrm{Bi}_{2} \mathrm{Te}_{3}-\mathrm{Sb}_{2} \mathrm{Te}_{3}$, имеющих сложное строение валентной зоны [2]. В частности, внесение в кристаллы $\mathrm{Bi}_{2} \mathrm{Te}_{3}-\mathrm{Sb}_{2} \mathrm{Te}_{3}$ p-типа примеси III группы, таких как галлий $\mathrm{Ga}$, индий $\mathrm{In}$, таллий $\mathrm{Tl}$, приводит не к увеличению концентрации дырок, а к уменьшению [2,3]. В связи с этим остается актуальной задача разностороннего изучения закономерностей изменения состояния электронной системы кристаллов $\mathrm{Bi}_{2} \mathrm{Te}_{3}-\mathrm{Sb}_{2} \mathrm{Te}_{3}$ в первую очередь от состава и температуры. Цель данной работы - исследование закономерностей изменения магнитной восприимчивости кристаллов $\mathrm{Bi}_{2} \mathrm{Te}_{3}-\mathrm{Sb}_{2} \mathrm{Te}_{3}$ в зависимости от соотношения компонент в составе твердого раствора и температуры, а также их интерпретация, учитывающая закономерности изменения температурных зависимостей удельной электропроводности.

\section{2. Кристаллы, образцы, техника эксперимента}

Исследовались монокристаллы твердых растворов $\mathrm{Bi}_{2} \mathrm{Te}_{3}-\mathrm{Sb}_{2} \mathrm{Te}_{3}$, содержащие 10, 25, 40, 50, 60 мол\% $\mathrm{Sb}_{2} \mathrm{Te}_{3}$, выращенные методом Чохральского в Институте металлургии и материаловедения им. А.А. Байкова РАН. В качестве исходных материалов использовались Те, $\mathrm{Sb}$, $\mathrm{Bi}$, содержащие $99.9999 \%$ по массе основного вещества. Химический состав выращенных монокристаллов определялся методом атомно-адсорбционной спектрометрии. Качество монокристаллов контролировалось методом рентгеновской дифракционной топографии [4].

Твердые растворы $\mathrm{Bi}_{2} \mathrm{Te}_{3}-\mathrm{Sb}_{2} \mathrm{Te}_{3}$ являются одноосными кристаллами. Кристалл $\mathrm{Bi}_{2} \mathrm{Te}_{3}$ обладает ромбоэдрической структурой с пространственной группой $\mathrm{D}_{3 \mathrm{~d}}^{5}(R 3 m)$, и его строение можно представить в виде набора слоев, перпендикулярных оси симметрии 3-го порядка $\mathrm{C}_{3}$ [1]. Возможен скол кристалла вдоль указанных слоев, т.е. по плоскости спайности, перпендикулярной $\mathrm{C}_{3}$. Образцы для магнитных измерений вырезались из слитков массой 200-300 г при помощи электроискровой резки и затем очищались травлением. Характерные размеры образцов для магнитных измерений $2 \times 2 \times 4$ мм.

В данной работе приведены и результаты исследований магнитной восприимчивости в диапазоне температур от 2 до $400 \mathrm{~K}$, которые проводились в магнитных полях до 30 кЭ на сверхпроводящем квантовом интерферометре Джозефсона (SQUID - маг- 
нетометре) при ориентации вектора напряженности магнитного поля $\mathrm{H}$ по отношению к $\mathrm{C}_{3}\left(\mathrm{H} \| \mathrm{C}_{3}\right)$. Для всех исследованных образцов наблюдалась линейная зависимость восприимчивости от напряженности поля до 30 кЭ. При ориентации $\mathrm{H} \| \mathrm{C}_{3}$ определяется $\chi_{\|}$. В настоящей работе измерения температурных зависимостей магнитной восприимчивости кристаллов твердых растворов $\mathrm{Bi}_{2} \mathrm{Te}_{3}-\mathrm{Sb}_{2} \mathrm{Te}_{3}$, в диапазоне от 2 до $400 \mathrm{~K}$, были выполнены на приборе, изготовленном компанией Quantum Design (USA). Полное наименование прибора - Magnetic Property Measurement System (MPMS MultiVu). В ходе исследования измерялся магнитный момент образца путем считывания выходных данных датчика SQUID, пока образец двигался вверх от положения инициализации через катушки SQUID. Показания напряжения, которые считываются как функция положения образца в катушках SQUID, представляют собой необработанные данные одного измерения. На каждой позиции образца в катушках MPMS MultiVu считывает выходное напряжение SQUID несколько раз, и затем возможно усреднение данных некоторого количества сканов для устранения случайных погрешностей. Калибровка магнитного момента для MPMS осуществляется путем измерения сигнала от палладиевого стандарта в соответствующем диапазоне магнитных полей. Стандарт представляет собой цилиндр $\sim 3$ мм диаметром и 3 мм высотой. Использование исследуемых образцов с указанными размерами способно обеспечить погрешность измерения, не превышающую $0.1 \%$.

\section{3. Обсуждение экспериментальных результатов}

Из экспериментальных данных, представленных на рис. 1 , следует, что наиболее общей закономерностью, характерной для всех исследованных температурных зависимостей магнитной восприимчивости кристаллов твердых растворов $\mathrm{Bi}_{2} \mathrm{Te}_{3}-\mathrm{Sb}_{2} \mathrm{Te}_{3}$, является увеличение диамагнитной восприимчивости в диапазоне температур от 2 до $15 \mathrm{~K}$, которое может быть связано с разориентацией магнитных моментов парамагнитной примеси, в остаточном количестве все же присутствующей в кристаллах, содержащих 99.9999\% основного вещества. Тогда при увеличении температуры до $15 \mathrm{~K}$ влияние парамагнитной примеси исчезает, и при более высоких температурах магнитная восприимчивость формируется вкладами ионного остова и свободных носителей заряда. Однако нельзя исключить, что могут быть и другие причины увеличения диамагнитной восприимчивости в низкотемпературной области. Как показали исследования, выполненные в работе [3], на температурных зависимостях удельной электропроводности кристаллов $\mathrm{Bi}_{2} \mathrm{Te}_{3}-\mathrm{Sb}_{2} \mathrm{Te}_{3}$ в большинстве случаев наблюдается слабо выраженная температурная зависимость вблизи $15 \mathrm{~K}$. В соответствии с подходом Блоха-Грюнайзена, который

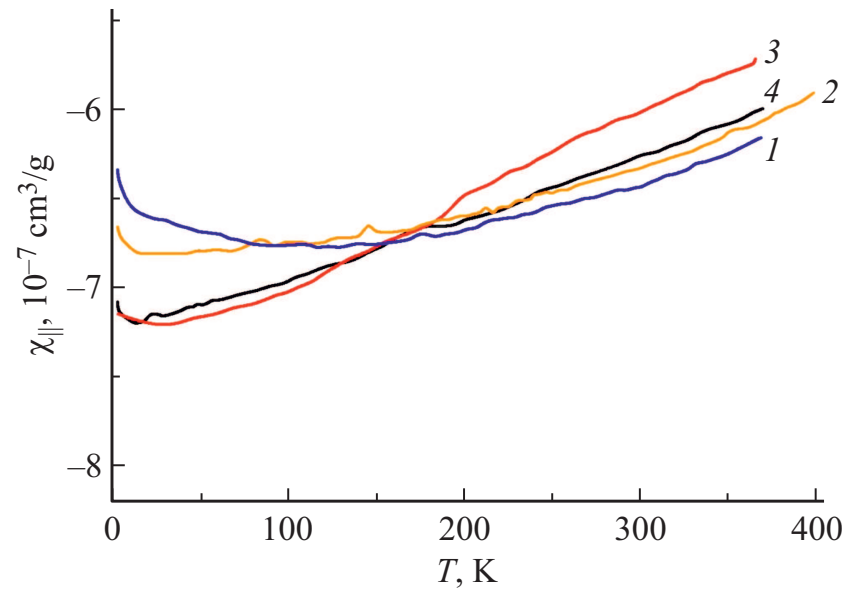

Рис. 1. Зависимость магнитной восприимчивости $\chi_{\|}$от температуры для различных значений $x$ в составе кристаллов твердого раствора $\left(\mathrm{Bi}_{2-x} \mathrm{Sb}_{x}\right) \mathrm{Te}_{3}: 1-0.2,2-0.5,3-1.2$, 4 - 1.0. Восприимчивость измерялась в поле 10 кЭ.

хорошо описывает температурное поведение удельного сопротивления в металлах, в области температур, примерно равных одной десятой от температуры Дебая, должно наблюдаться быстрое, пропорциональное пятой степени температуры уменьшение времени релаксации с ростом температуры, обусловленное усилением колебаний кристаллической решетки, ведущее к уменьшению электропроводности в кристаллах с низкой долей рассеяния на примеси. Для кристаллов $\mathrm{Bi}_{2} \mathrm{Te}_{3}$ температура Дебая равна $155 \mathrm{~K}$. Таким образом, наблюдающаяся в кристаллах $\mathrm{Bi}_{2} \mathrm{Te}_{3}$ слабая зависимость электропроводности с ростом температуры, а в ряде случаев даже ее небольшое увеличение, в диапазоне от 4 до $15 \mathrm{~K}$ является фактом, указывающим на наличие дополнительных механизмов рассеяния носителей заряда, а также на возможный рост концентрации свободных дырок, который может быть обусловлен переходом электронов на акцепторные примесные уровни, расположенные в непосредственной близости к потолку валентной зоны. Отметим также, что, как следует из рис. 1, в кристалле $\mathrm{Bi}_{2} \mathrm{Te}_{3}-\mathrm{Sb}_{2} \mathrm{Te}_{3}$, содержащем $10 \% \mathrm{Bi}_{2} \mathrm{Te}_{3}$, увеличение диамагнитной восприимчивости с ростом температуры завершается при температуре $80 \mathrm{~K}$, при которой, как следует из данных, приведенных в работе [1], в $\mathrm{Bi}_{2} \mathrm{Te}_{3}$ останавливается уменьшение коэффициента Холла, и начинается его аномальный рост, вплоть до температур перехода к собственной проводимости. Если физическая причина поведения электропроводности и магнитной восприимчивости в области низких температур едина, то вероятно, что и увеличение диамагнитной восприимчивости кристаллов $\mathrm{Bi}_{2} \mathrm{Te}_{3}-\mathrm{Sb}_{2} \mathrm{Te}_{3}$ в диапазоне от 4 до $15 \mathrm{~K}$ может быть частично обусловлено увеличением концентрации легких дырок. В этом случае магнитный отклик легких дырок имеет диамагнитный характер. 


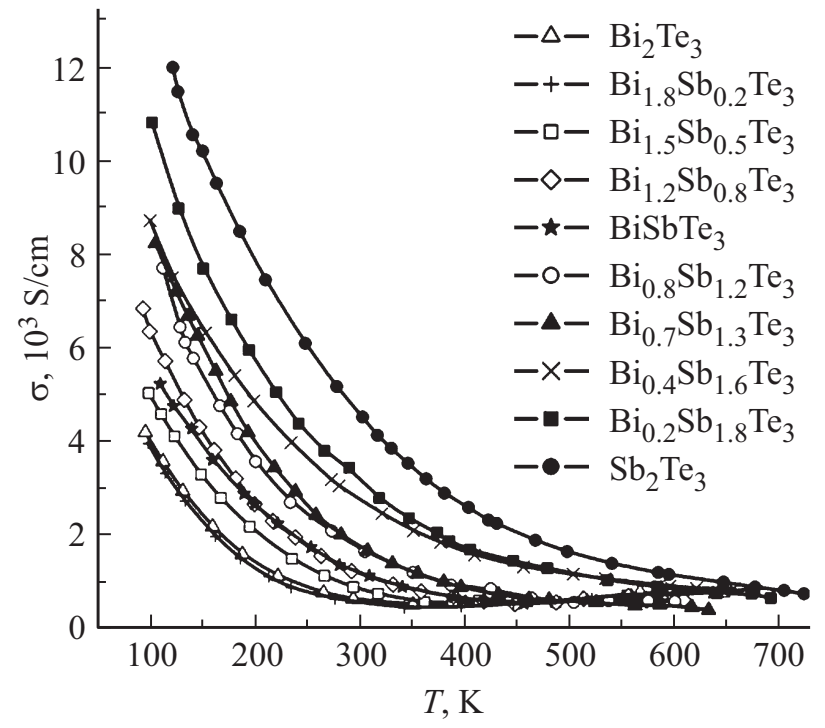

Рис. 2. Зависимости электропроводности от состава и температуры кристаллов твердого раствора $\mathrm{Bi}_{2} \mathrm{Te}_{3}-\mathrm{Sb}_{2} \mathrm{Te}_{3}$ [4]. Электропроводность определялась вдоль направления, перпендикулярного тригональной оси кристалла $\mathrm{C}_{3}$.

Другим фактом, свидетельствующим в пользу диамагнитного характера отклика легких дырок на внешнее магнитное поле в кристаллах $\mathrm{Bi}_{2} \mathrm{Te}_{3}-\mathrm{Sb}_{2} \mathrm{Te}_{3}$, является наблюдаемое изменение величины магнитной восприимчивости кристаллов при температуре $15 \mathrm{~K}$, в зависимости от процентного содержания теллурида сурьмы. Так, из рис. 1 видно, что увеличение содержания $\mathrm{Sb}_{2} \mathrm{Te}_{3}$ в кристаллах $\mathrm{Bi}_{2} \mathrm{Te}_{3}-\mathrm{Sb}_{2} \mathrm{Te}_{3}$ до 60 мол\% приводит к увеличению диамагнитной восприимчивости при температуре $15 \mathrm{~K}$. Причиной этого может быть увеличение концентрации легких диамагнитных дырок. Как видно из рис. 2, при увеличении содержания $\mathrm{Sb}_{2} \mathrm{Te}_{3}$ в составе твердого раствора происходит увеличение удельной электропроводности кристаллов $\mathrm{Bi}_{2} \mathrm{Te}_{3}-\mathrm{Sb}_{2} \mathrm{Te}_{3}$ [5], особенно ярко выраженное при низких температурах, которое связано с увеличением концентрации легких дырок. Действительно, как видно из таблицы, значения концентрации дырок, определенные по эффекту

Состав, магнитная восприимчивость $\chi$ кристаллов $\mathrm{Bi}_{2} \mathrm{Te}_{3}-\mathrm{Sb}_{2} \mathrm{Te}_{3}, T=291 \mathrm{~K}$, и концентрация дырок $p$, измеренная при температуре $78 \mathrm{~K}$

\begin{tabular}{c|c|c|c|c}
\hline $\begin{array}{c}\text { Состав } \\
\text { кристаллов }\end{array}$ & $\begin{array}{c}\% \mathrm{Sb}_{2} \mathrm{Te}_{3} \\
\text { в } \mathrm{Bi}_{2} \mathrm{Te}_{3}\end{array}$ & $\begin{array}{c}\chi_{\perp} \cdot 10^{6}, \\
\mathrm{~cm}^{3} / \Gamma\end{array}$ & $\begin{array}{c}\chi_{\|} \cdot 10^{6}, \\
\mathrm{~cm}^{3} / \Gamma\end{array}$ & $\begin{array}{c}p \cdot 10^{-19} \\
\mathrm{~cm}^{-3}\end{array}$ \\
\hline $\mathrm{Bi}_{2} \mathrm{Te}_{3}$ & 0 & -0.423 & -0.676 & \\
$\mathrm{Bi}_{1.8} \mathrm{Sb}_{0.2} \mathrm{Te}_{3}$ & 10 & -0.456 & -0.744 & 0.8 \\
$\mathrm{Bi}_{1.5} \mathrm{Sb}_{0.5} \mathrm{Te}_{3}$ & 25 & -0.433 & -0.686 & 0.9 \\
$\mathrm{BiSbTe}_{3}$ & 50 & -0.412 & -0.623 & 1.6 \\
$\mathrm{Bi}_{0.8} \mathrm{Sb}_{1.2} \mathrm{Te}_{3}$ & 60 & -0.407 & -0.596 & 2.3 \\
$\mathrm{Bi}_{0.6} \mathrm{Sb}_{1.4} \mathrm{Te}_{3}$ & 70 & -0.368 & -0.457 & 4.2 \\
$\mathrm{Bi}_{0.4} \mathrm{Sb}_{1.6} \mathrm{Te}_{3}$ & 80 & -0.342 & -0.357 & 4.8
\end{tabular}

Холла при температуре $78 \mathrm{~K}$, увеличиваются по мере увеличения процентного содержания $\mathrm{Sb}_{2} \mathrm{Te}_{3}$. Таким образом, увеличение удельной электропроводности и концентрации свободных носителей заряда сопровождается увеличением диамагнитной восприимчивости кристалла, из чего также можно сделать заключение о результирующей диамагнитной восприимчивости легких дырок.

Отметим, что анализируемые экспериментальные данные характеризуют температурное изменение состояния электронной системы именно в валентной зоне. Рост электропроводности и концентрации легких дырок, по мере увеличения содержания теллурида сурьмы в составе твердого раствора $\mathrm{Bi}_{2} \mathrm{Te}_{3}-\mathrm{Sb}_{2} \mathrm{Te}_{3}$, свидетельствует о смещении уровня химического потенциала в глубину валентной зоны, что сопровождается увеличением количества не заполненных состояний в валентной зоне. При этом увеличивается и диамагнитная восприимчивость кристалла. Этот экспериментальный факт не согласуется с представлениями о возможном доминировании диамагнитного вклада полностью заполненной валентной зоны, поскольку в случае ее частичного заполнения диамагнитный отклик кристалла должен был бы уменьшиться, а не возрасти, как это наблюдается при увеличении содержания $\mathrm{Sb}_{2} \mathrm{Te}_{3}$, что отражено на рис. 1 .

Экспериментальные данные, представленные на рис. 1, содержат еще одно указание на диамагнитный характер отклика легких дырок в кристаллах $\mathrm{Bi}_{2} \mathrm{Te}_{3}-\mathrm{Sb}_{2} \mathrm{Te}_{3}$. Оно вытекает из сопоставления температурных зависимостей магнитной восприимчивости и удельной электропроводности. Так, из рис. 1 и 2 видно, что результирующая диамагнитная восприимчивость кристаллов уменьшается в том же температурном диапазоне, в котором происходит уменьшение удельной электропроводности. Известно, что для кристаллов $\mathrm{Bi}_{2} \mathrm{Te}_{3}-\mathrm{Sb}_{2} \mathrm{Te}_{3}$, уменьшение удельной электропроводности происходит в диапазоне температур проявления аномального поведения коэффициента Холла, а именно его увеличения, при возрастании температуры, которое заканчивается в кристаллах $\mathrm{Bi}_{2} \mathrm{Te}_{3}$ переходом к собственной проводимости при температуре $\sim 300 \mathrm{~K}$, a в кристаллах $\mathrm{Sb}_{2} \mathrm{Te}_{3}$ при температуре $600 \mathrm{~K}$ [1]. Наиболее аргументированное объяснение аномальной температурной зависимости коэффициента Холла в кристаллах $\mathrm{Bi}_{2} \mathrm{Te}_{3}-\mathrm{Sb}_{2} \mathrm{Te}_{3}$ связано с процессом перераспределения дырок между экстремумами валентной зоны, вследствие чего концентрация легких, подвижных дырок с ростом температуры уменьшается, а концентрация тяжелых, малоподвижных дырок увеличивается. В работе [6] представлены данные экспериментального исследования спектров отражения кристалла $\mathrm{Bi}_{2} \mathrm{Te}_{3}-\mathrm{Sb}_{2} \mathrm{Te}_{3}$, содержащего 60\% теллурида сурьмы при различных температурах. Из спектров видно, что при увеличении температуры наблюдается уменьшение энергии межзонных переходов, идущих с уровня химического потенциала в зону проводимости, обусловленное его смещением к потолку валентной 
зоны, которое, вероятно, происходит вследствие процесса перераспределения дырок между неэквивалентными экстремумами валентной зоны. Можно утверждать, что данные оптических исследований являются экспериментальным подтверждением существования процесса перераспределения дырок в валентной зоне кристаллов $\mathrm{Bi}_{2} \mathrm{Te}_{3}-\mathrm{Sb}_{2} \mathrm{Te}_{3}$, являющегося причиной аномальной температурной зависимости коэффициента Холла.

Таким образом, процесс перераспределения дырок должен давать вклад и в уменьшение удельной электропроводности с ростом температуры, наблюдающееся на рис. 2. Анализ, выполненный в работе [7], показывает, что уменьшение электропроводности с ростом температуры кристаллов $\mathrm{Bi}_{2} \mathrm{Te}_{3}-\mathrm{Sb}_{2} \mathrm{Te}_{3}$ оказывается настолько значительным, что не может быть объяснено только уменьшением времени релаксации носителей заряда и увеличением их эффективной массы. Также требуется учитывать и влияние перераспределения свободных носителей заряда между экстремумами валентной зоны, приводящее к уменьшению легких подвижных дырок, дающих основной вклад в электропроводность. Поскольку величина магнитной восприимчивости кристалла формируется и вкладом свободных носителей заряда, то этот же процесс влияет на ход температурной зависимости магнитной восприимчивости. Действительно, как видно из рис. 1, в диапазоне температур от 15 до $400 \mathrm{~K}$, в кристаллах $\mathrm{Bi}_{2} \mathrm{Te}_{3}-\mathrm{Sb}_{2} \mathrm{Te}_{3}$, содержащих 50 и 60 мол\% $\% \mathrm{Sb}_{2} \mathrm{Te}_{3}$, происходит уменьшение диамагнитной восприимчивости, которое можно объяснить уменьшением концентрации легких диамагнитных дырок. Следовательно, из сопоставления хода температурных зависимостей удельной электропроводности и магнитной восприимчивости также можно сделать вывод о диамагнитном характере отклика легких дырок в кристаллах $\mathrm{Bi}_{2} \mathrm{Te}_{3}-\mathrm{Sb}_{2} \mathrm{Te}_{3}$.

\section{4. Заключение}

В заключение отметим, что рассмотренная корреляция температурных зависимостей магнитной восприимчивости и удельной электропроводности, обусловленная реакцией кристаллов $\mathrm{Bi}_{2} \mathrm{Te}_{3}-\mathrm{Sb}_{2} \mathrm{Te}_{3}$ на электрические, магнитные и электромагнитные поля, позволяет использовать температурные зависимости магнитной восприимчивости для детализации процессов, происходящих в их электронной системе, и изменении их интенсивности при варьировании содержания $\mathrm{Sb}_{2} \mathrm{Te}_{3}$ и температуры. При этом вывод о диамагнитном характере магнитной восприимчивости легких дырок имеет определяющее значение для интерпретации температурных зависимостей магнитной восприимчивости кристаллов $\mathrm{Bi}_{2} \mathrm{Te}_{3}-\mathrm{Sb}_{2} \mathrm{Te}_{3}$, содержащих более 60 мол\% $\mathrm{Sb}_{2} \mathrm{Te}_{3}$, в которых наблюдаются особенности в поведении температурных зависимостей удельной электропроводности, анализ возможных причин возникнове- ния которых дан в работе [8]. Именно в этих кристаллах, вследствие повышенного содержания $\mathrm{Sb}_{2} \mathrm{Te}_{3}$, происходит увеличение концентрации свободных носителей заряда, и, как следствие, энергии плазмона, которая приближается к энергии запрещенной зоны, что приводит к усилению электрон-плазмонного взаимодействия. Наряду с электрон-фононным оно способно оказывать воздействие на электронную систему кристалла $[9,10]$, обеспечивая появление особенностей в поведении ряда физических величин, характеризующих ее состояние.

\section{Финансирование работы}

Работа выполнена в рамках гранта 15-2021 ФГБОУ ВО „Забайкальский государственный университет“, выделенного на поддержку научных подразделений Советом по научной и инновационной деятельности.

\section{Конфликт интересов}

Авторы заявляют, что у них нет конфликта интересов.

\section{Список литературы}

[1] Б.М. Гольцман, В.А. Кудинов, И.А. Смирнов. Полупроводниковые термоэлектрические материалы на основе $B i_{2} T e$ (М., Наука, 1972).

[2] В.А. Кульбачинский, В.Г. Кытин, П.М. Тарасов. ЖЭТФ, 134 (4), 700 (2010).

[3] А.А. Кудряшов. Канд. дис. физ.-мат. наук: 01.04.09 Физика низких температур (М., МГУ, 2016).

[4] И.Х. Абрикосов, Л.Д. Иванова, О.Г. Карпинский, Т.Е. Свечникова, С.Н. Чижевская. Неорг. матер., 13 (4), 641 (1977).

[5] Л.Д. Иванова, Ю.В. Гранаткина. Неорг. матер., 36, 810 (2000).

[6] Н.П. Степанов, А.А. Калашников, О.Н. Урюпин. ФТП, $55(7), 586$ (2021).

[7] Н.П. Степанов, А.С. Лозовская, Л.Э. Степанова. Изв. вузов. Физика, 61 (8), 55 (2018).

[8] Н.П. Степанов. ФТП, 54 (1), 13 (2020).

[9] Н.С. Барышев. ФТП, 9 (10), 2023 (1975).

[10] Ч. Киттель. Введение в физику твердого тела (М., Наука, 1978) гл. 6, с. 742. 


\section{Temperature dependences of electrical conductivity and magnetic susceptibility of crystals of solid solution $\mathrm{Sb}_{2} \mathrm{Te}_{3}-\mathrm{Bi}_{2} \mathrm{Te}_{3}$}

N.P. Stepanov ${ }^{1,3}$, V.Yu. Nalivkin ${ }^{1}$, A.K. Gilfanov ${ }^{1}$, A.A. Kalashnikov ${ }^{2}$, E.N. Trubitsyna ${ }^{3}$

${ }^{1}$ Zabaikalsky State University, 672036 Chita, Russia

${ }^{2}$ Trans-Baikal Institute of Railway Transport, 672040 Chita, Russia

${ }^{3}$ Zabaikalsky Institute of Entrepreneurship, 672000 Chita, Russia

Abstract Solid solutions $\mathrm{Bi}_{2} \mathrm{Te}_{3}-\mathrm{Sb}_{2} \mathrm{Te}_{3}$ continue to be the subject of numerous and versatile experimental studies due to their practical importance for thermoelectric materials science. In this regard, the problem of studying the regularities of changes in the state of the electronic system of these semiconductors from composition and temperature remains urgent. This paper presents the results of studying the temperature dependences of the magnetic susceptibility of $\mathrm{Bi}_{2} \mathrm{Te}_{3}-\mathrm{Sb}_{2} \mathrm{Te}_{3}$ crystals containing 10 , $25,40,50,60 \mathrm{~mol} \% \mathrm{Sb}_{2} \mathrm{Te}_{3}$. The correlation of the behavior of the temperature dependences of the magnetic susceptibility and electrical conductivity is analyzed.

Продолжение публикации материалов Конференции см. в № 1/22 